\title{
Physical Fitness of Paraplegics in Full Wheelchair Marathon Racing
}

\author{
K. Asayama, M.D., ${ }^{1}$ Y. Nakamura, M.D., ${ }^{2,3}$ H. Ogata, M.D., ${ }^{1}$ K. Hatada, \\ M.D., ${ }^{3}$ H. Okuma, M.D. ${ }^{1}$ and Y. Deguchi, M.D. ${ }^{4}$ \\ ${ }^{1}$ Department of Rehabilitation Medicine, University of Occupational and Environ- \\ mental Health, Fapan, Kitakyushu 807 Fapan, ${ }^{2}$ Fapan Sun Industries, Fapan Sports \\ Association for the Disabled, Beppu, 874-01 fapan, ${ }^{3}$ Oita Nakamura Hospital, \\ Oita, 870 Fapan, ${ }^{4}$ Department of Orthopedics, Miyazaki Medical College, \\ Miyazaki 889-16 fapan
}

\section{Summary}

The wheelchair marathon is one of the most difficult sports for participants with much uncertainty regarding the security of the paraplegics. The physical fitness of paraplegics has been examined regularly since The Oita International Wheelchair Marathon (half marathon) was inaugurated (1981). A full marathon (42.195 km) was adopted at The 3rd Meeting (1983). The individual equations between heart rate $(H R)$ and oxygen consumption $\dot{V} \mathrm{O}_{2}$ were drawn from the preliminary test on the subjects who were expected to be among the top finishers in these races. $\dot{V} \mathrm{O}_{2}$ during these races was indirectly estimated and showed a fairly low value $(35.0 \pm 3.8 \mathrm{ml} / \mathrm{kg} / \mathrm{min}$ in the full race, $32.7 \pm 6.3 \mathrm{ml} / \mathrm{kg} / \mathrm{min}$ in the half race respectively) in comparison with able-bodied elite runners. However, the paraplegic participants had extremely high $H R(171.6 \pm 20.5$ beats/min, $168.1 \pm 9.8)$ continuously throughout the race. Though the ratio of active muscle mass of arms to legs in paraplegic athletes may approximate to near equal, paraplegic arms seem to exert physiologically and mechanically less efficient power. There were no significant differences in physical fitness between the full and the half marathon elite finishers. The cardiovascular function of paraplegic athletes may well be ranked among those of able-bodied athletes in their fitness. Full wheelchair marathon seems to be safe if it is held in an appropriate environment.

Key words: Paraplegia; Wheelchair marathon; Physical fitness; Heart rate recording; Oxygen consumption.

\section{Introduction}

Wheelchair bound paraplegics spend a sedentary life in their wheelchairs throughout almost the whole day. Their activities of daily living (ADL) are very limited. One hesitates to assign vigorous physical exercises to paraplegics owing to their many physiological handicaps. These situations eventually lead to a 'disuse syndrome' which develops into more serious disabilities and causes a deterioration in their physical fitness. Physical fitness is determined by the 
intensity, the duration and the frequency of exercise. A paraplegic wheelchair marathon requires maximum endurance power for a long duration. In commemoration of the year of the disabled, The 1st Oita International Wheelchair Marathon was held in 1981. At this time the physical fitness of paraplegics during the race was evaluated by using participants who were asked at random to be testees (Asayama et al., 1984). The following year, the same study was made on the competitors who were thought to have the best chance of finishing at the top in the second meeting. These two meetings were so called half marathons $(21.0975 \mathrm{~km})$. Also, the data was used to provide a rational basis for taking part in the full marathon $(42 \cdot 195 \mathrm{~km})$ which was to take place at the 3rd meeting (1983). This full marathon was officially recognised by ISMGF (International Stoke Mandeville Game's Federation). Many elite wheelchair racers from 14 countries participated (Table 1). The same examination used at the time of the previous two meetings was carried out on the full marathon participants who had also been expected to be among the top finishers. This paper presents the results seen mainly in a full wheelchair marathon, the comparison of the fitness and physical characteristics between the participants of the full and the half marathon, and also between the best and lower finishers. The risk of paraplegic racing is also discussed.

\section{Outline of the 3rd Oita International Wheelchair Marathon}

Two different races were held simultaneously; one was a full marathon, the other a half marathon. Classification of disability was used for the half marathon in accordance with ISMGF, but no classification was used for the full marathon. Table 2 shows the diagnosis of the participants. The official time of the first prize winner (25-year-old, male, West Germany) in the full marathon was 2 hours $7 \mathrm{~min} 54 \mathrm{sec}$ and the last finisher's (38-year-old, male, Japan) the time was 3 hours $5 \mathrm{~min} 20 \mathrm{sec}$. There was a regulation time for certain distances. The course was not circular but up and down a fixed course which was almost

Table 1 The number of participants by country at The 3rd Oita International Wheelchair Marathon, ( ) females

\begin{tabular}{lccc}
\hline Country & Full Marathon & Half Marathon & Total \\
\hline Australia & 1 & & 1 \\
Austria & 1 & 2 & 1 \\
Belgium & & 2 & 2 \\
Canada & 5 & $46(4)$ & 5 \\
Hong Kong & $41(1)$ & 3 & 87 \\
Japan & & 3 & 3 \\
Korea & 2 & 1 & 3 \\
Kuwait & & 1 & 4 \\
Macau & 2 & $1(1)$ & 1 \\
Norway & $4(2)$ & & 2 \\
Sri Lanka & 1 & $61(5)$ & 5 \\
Switzerland & USA & & $118(8)$ \\
West Germany & & &
\end{tabular}


Table 2 The number of participants by diagnosis at The 3rd Oita International Wheelchair Marathon, ( ): female

\begin{tabular}{lllc}
\hline Diagnosis & Full marathon & Half marathon & Total \\
\hline Spinal Injury & $46(2)$ & $39(3)$ & $85(5)$ \\
Poliomyelitis & $10(1)$ & $16(2)$ & $26(3)$ \\
Amputee, A/K s & 1 & 1 & 2 \\
Cerebral Palsy & 0 & 5 & 5 \\
Total & $57(3)$ & $61(5)$ & $118(8)$ \\
\hline
\end{tabular}

flat except for steep slopes leading up to three bridges. The weather was windy, but fine (ambient temperature; $10 \cdot 8^{\circ} \mathrm{C}$, relative humidity; $54 \%$, wind; $3.7 \mathrm{~m} / \mathrm{sec}$ ).

\section{Subjects and methods}

Eleven paraplegic competitors who were expected to be among the top finishers in the full marathon, including one female, were selected as testees in the treadmill work test which was held 2 days before the race. They consisted of seven paraplegics resulting from spinal cord injury, from the 4th thoracic level to the 1 st lumbar level, and four competitors who had had poliomyelitis. The mean age of subjects was $30 \cdot 7$ years (ranged: 19 to 46 years). The mean body weight of subjects was $58.3 \mathrm{~kg}$ ( 48 to $75 \mathrm{~kg}$ ). The mean duration since injury or disease was 20 years ( 1 year 9 months to 45 years).

The preliminary treadmill work test consisted of propelling their specially designed wheelchair to be used in the race on a wheelchair treadmill at a belt speed of $60 \mathrm{~m} / \mathrm{min}$. Each subject was requested at first to propel for 3 minutes on a tilted treadmill ( 2 degrees). The tilting was subsequently increased by 2 degrees every 3 minutes up to the maximum of 6 degrees. Expired gas was collected in a Douglas bag during the final one minute of each tilted work load and $\mathrm{O}_{2}$ and $\mathrm{CO}_{2}$ contents were analysed with a gas analyzer (1H21 A, NEC-Sanei). The heart rate (HR) was continuously monitored by telemetric ECG equipment. The relationship between $\mathrm{HR}$ and $\mathrm{VO}_{2}$ was calculated from the $\mathrm{O}_{2}$ consumption and $\mathrm{HR}$, and the regression equation for individual subjects was used to indirectly estimate the $\mathrm{VO}_{2}$ during the race. The mean weight of the wheelchair was $8.4 \mathrm{~kg}(6.8$ to $12.0 \mathrm{~kg})$. The room temperature was $18.0^{\circ} \mathrm{C}$.

Nine subjects out of 11 were asked to install a small memory box beneath the seat of their wheelchair or attach it to their leg to record the entire HR at intervals of $1 \mathrm{~min}$ during the race. Two different types of memory box (Pulse Counter, Takei-Kiki) were used: one weighed $450 \mathrm{~g}$ and the other $280 \mathrm{~g}$. The box was connected to the chest wall of the subject by electrode wires. Great care was taken to place the electrodes so as not to hinder the movements of the subjects. However, the contact of one competitor's chest electrode was faulty for some unknown reason, and another competitor retired due to trouble with his wheelchair caster. Therefore, seven competitor's HR recordings were obtained during the race.

Routine physical characteristics were also measured and the differences between good finishers and the lower ones (except those who retired from the race) were compared. Body fat $(\%)$ was calculated using the formula of Wilson 
et al. (1981) by measuring the skin fold at the triceps, subscapula and suprailium. Predicted lung vital capacity (LVC) was estimated by the equation of Baldwin et al. (1950). The method of pulling and pushing an instrument (The Bullworker) was used to measure gross arm strength. Finally, these two values of strength were averaged.

The same studies were made on elite half marathon competitors one year before (1982). HR recordings in eight subjects, including one female, were obtained. The subjects consisted of seven paraplegics from the 9th thoracic level to the $1 \mathrm{st}$ lumbar level, and one post poliomyelitis. The mean age was 31.4 years ( 24 to 40 years). One subject placed 2 nd and the others finished somewhere between the 2 nd and 18th place. The course was the same as used in the full marathon, but only half the distance. The weather was fine (ambient temperature; $14.9^{\circ} \mathrm{C}$, relative humidity; $50.0 \%$, wind; $5.2 \mathrm{~m} / \mathrm{sec}$ ).

\section{Results}

The relationship between the work load on the treadmill and HR during the preliminary test for full marathon competitors is shown in Figure 1. The relationship between the $\mathrm{HR}$ (the abscissa: $\mathrm{X}$ beats $/ \mathrm{min}$ ) and $\mathrm{V}_{2}$ (the ordinate: $\mathrm{Y} \mathrm{ml} / \mathrm{kg} / \mathrm{min}$ ) during the treadmill work load is shown in Figure 2. The regression equation for overall subjects was expressed as: $\mathrm{Y}=-14.6+0.29 \mathrm{X},(\mathrm{p}<0.001)$. The regression equation for the individual subjects who could finish the race are shown in Table 3. The HR during the race was extremely high with a mean value of 171.6 beats/min $(S D \pm 20.5)$ and sometimes even rising to more than 200 beats/min. However, their HR was relatively constant throughout the race, though some runner's HR increased when approaching the goal suggesting the effort some put into the final spurt while other's HR decreased gradually due to tiredness. An individual's mean $\mathrm{HR}$ was used to estimate $\mathrm{VO}_{2}$ during the race by applying each participants' equation (Table 3). The mean $\mathrm{V}_{2}$ during

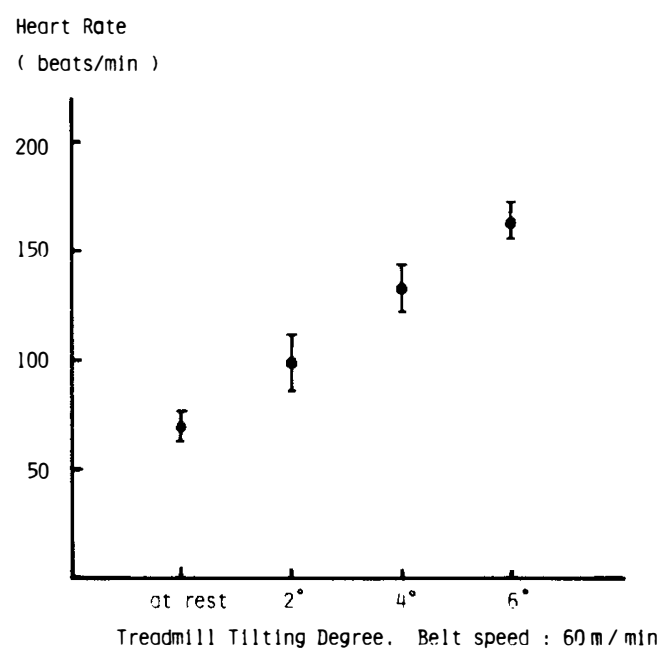

Figure 1. Relationship between work load and heart rate during wheelchair treadmill test on paraplegic subjects. Points and vertical bars are mean $\pm S D$ of 11 subjects. 


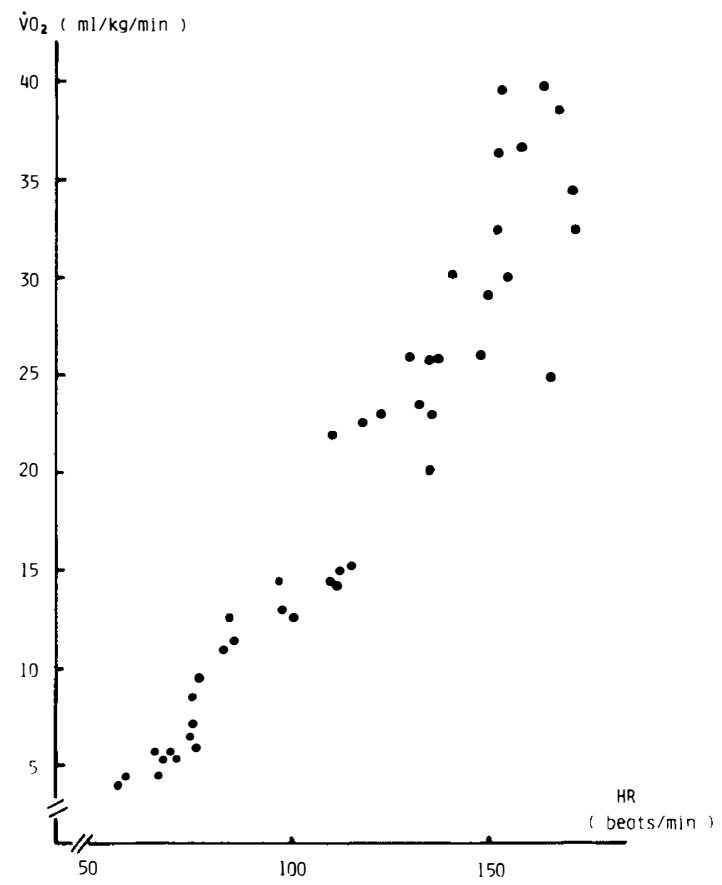

Figure 2. Relationship between heart rate $(\mathrm{HR})$ and oxygen consumption $\left(\dot{\mathrm{VO}}_{2}\right)$ during wheelchair treadmill work $(n=11)$.

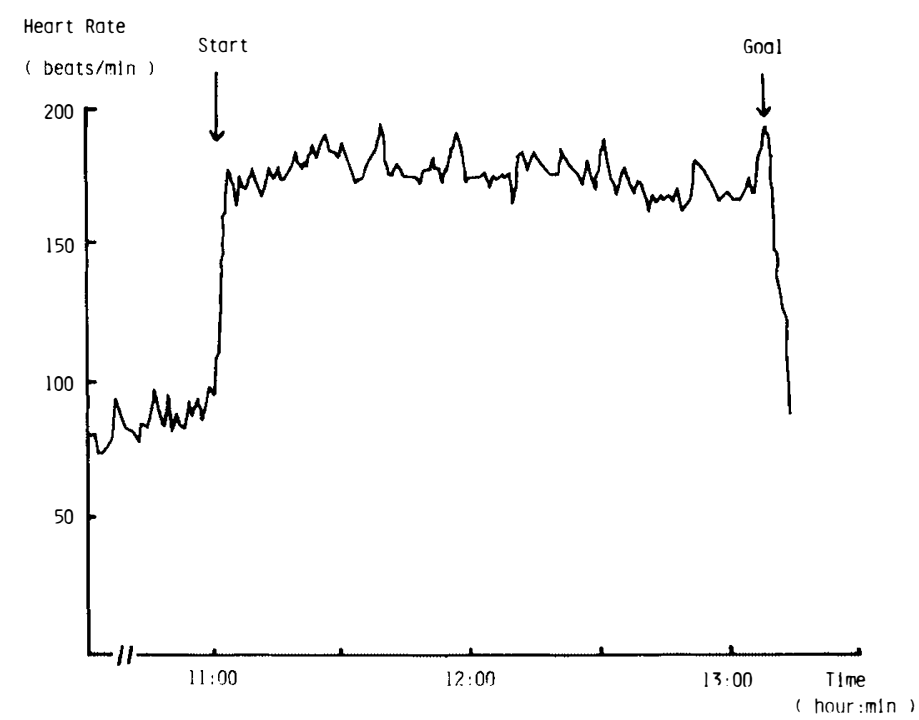

Figure 3. A typical heart rate recording during the wheelchair full marathon. Subject: R.H. 26 year-old paraplegic, complete spinal cord injury at 10th thoracic level. Official time; 2:7:56.

the race was $35.0 \mathrm{ml} / \mathrm{kg} / \mathrm{min}(\mathrm{SD} \pm 3 \cdot 8)$. The highest estimated value was 41 $\mathrm{ml} / \mathrm{kg} / \mathrm{min}$. Figure 3 shows a typical pattern of the HR recording during the race. Table 4 shows the physical characteristics of the competitors in the full 


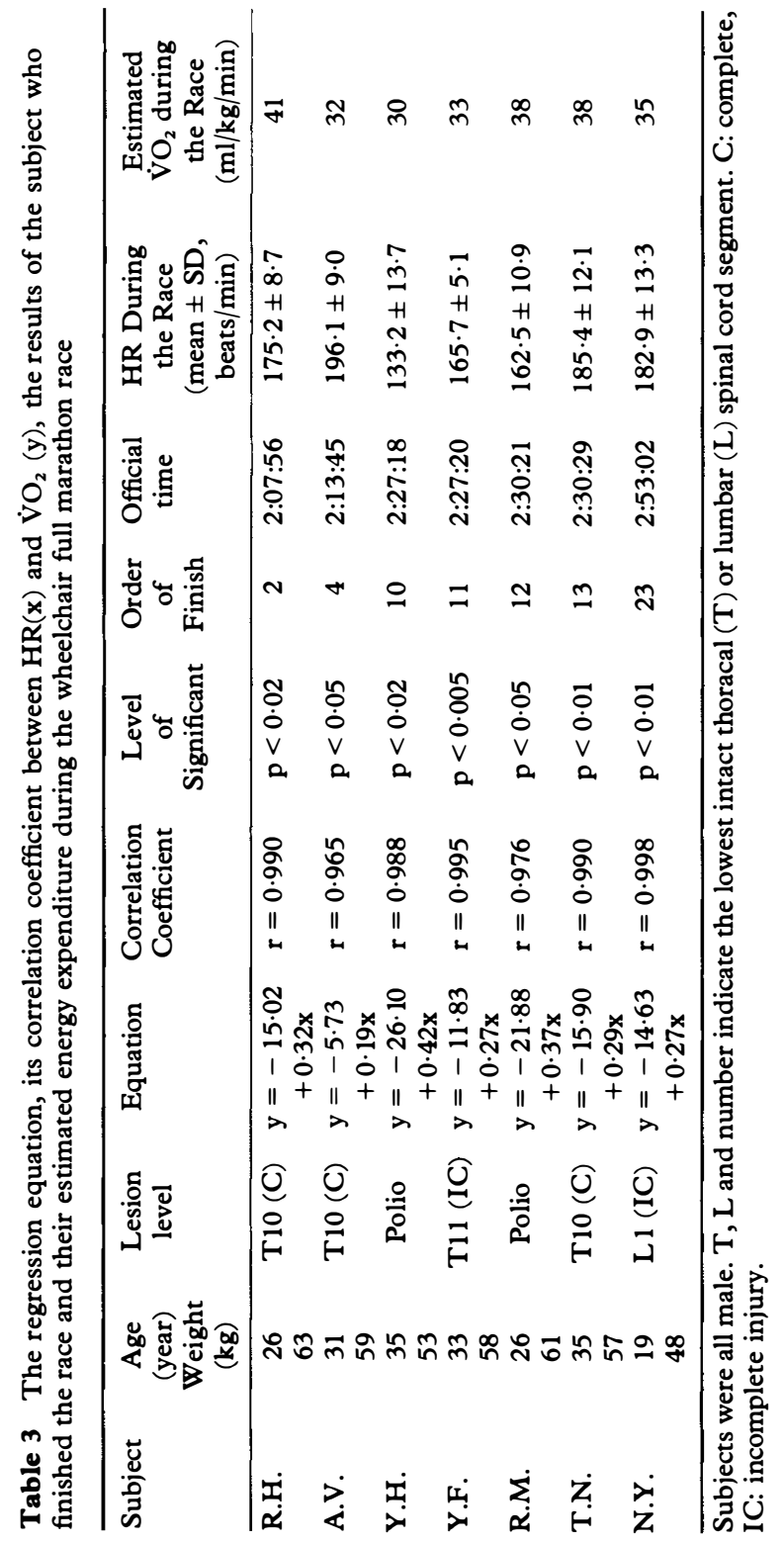


marathon (1983) and the half marathon (1982) and the differences between good finishers and lower ones. LVC of elite full racers is significantly greater than those in the lower ranks $(p<0.02)$. In the half marathon, the elite group is significantly greater in the LVC related indexes, arm girth and grasping force ( $\mathrm{p}<0.05,0.05,0.005$ respectively).

The results of the elite runners in the half marathon were as follows; the mean HR: $168 \cdot 1$ beats $/ \mathrm{min}\left(152.0\right.$ to $178 \cdot 3$ ), the mean $\mathrm{VO}_{2}: 32.7 \mathrm{ml} / \mathrm{kg} / \mathrm{min}$ (23 to 43 ) and official time ranged from $61 \mathrm{~min} 12 \mathrm{sec}$ to $79 \mathrm{~min} 24 \mathrm{sec}$. There were no significant differences in any of the indexes between the full and the half marathon competitors on whom entire recordings during the races were taken.

\section{Discussion}

The amount of activity of ordinary paraplegics seems to be very low. Hjeltness et al. (1979) reported that their activity had reached less than 24 per cent of their maximum work load. This amount is far less than is required to maintain their cardiovascular function or to improve physical fitness. Sports has been recommended for paraplegics to improve their general condition, and just as jogging has become popular among the able-bodied, wheelchair racing has come into vogue amongst paraplegics. A marathon requires continued high $\mathrm{HR}$ and a great amount of muscular endurance. The cardiovascular burden to paraplegics during exercise is considered to be much more than that for able-bodied persons because of limited muscular exertion in the upper extremities. Moreover, paraplegics have many other physical impairments such as a low basal metabolic rate, urinary tract trouble, decubitus pro skin, etc. These have given us cause to feel uneasy when paraplagics take part in a marathon race. However, endurance exercise such as a marathon is a kind of aerobic exercise which should be maintained in a steady state condition with submaximum range during a race. Measurement of $\mathrm{VO}_{2}$ during endurance type exercising is essential and recording of HR is a simple way to estimate the amount of work load upon the cardiovascular system. HR variation depends mainly upon intensity and type of muscular work during exercising. A linear relationship between work load and $\mathrm{VO}_{2}$ as well as HR exists over a wide range of values (Andersen and Smith-Sivertsen, 1966; Åstrand and Rodahl, 1977). This relationship has been proved to provide a reasonably accurate prediction in well-trained subjects (Rowell et al., 1964). $\dot{\mathrm{VO}}_{2}$ can be predicted by an extrapolation method from the participants' equation of the relationship between $\mathrm{HR}$ and $\mathrm{VO}_{2}$ at a submaximal work load (Wyndham and Ward, 1957). With these rationale, $\dot{\mathrm{VO}}_{2}$ during the race was estimated indirectly by using each $\mathrm{HR}$ recorded during the entire race which was applied to an individual's equation measured at the time of the preliminary treadmill work load.

When an exercise is performed by arms only, $\mathrm{V}_{2}$ remains relatively low in spite of increased HR. This is quite different from an exercise performed only with the legs. The physiological response to work with the arms is mechanically less efficient and $\dot{\mathrm{V}} \mathrm{O}_{2} \max \left(\right.$ maximum $\dot{\mathrm{VO}}_{2}$ ) is less by about 35 per cent than that of similar exercise with the legs (Åstrand and Saltin, 1961; Asmussen and Hemmingsen, 1958; Bar-Or and Zwiren, 1975; Davies and Sargeant, 1974; Stenberg et al., 1967; Vokac et al., 1975). Furthermore, a wheelchair ergometer is mechanically less efficient than the crank ergometer which is used for arm 
Table 4 Physical characteristics of wheelchair participants who placed in the top ten and lower rankings (mean $\pm \mathrm{SD}$ )

\begin{tabular}{|c|c|c|c|c|}
\hline \multirow[b]{2}{*}{ Variable } & \multicolumn{2}{|c|}{ Full Marathon (1983) } & \multicolumn{2}{|c|}{ Half Marathon (1982) } \\
\hline & $\begin{array}{c}\text { top } \\
(\mathrm{n}=10)\end{array}$ & $\begin{array}{c}\text { lower } \\
(n=13)\end{array}$ & $\begin{array}{c}\text { top } \\
(\mathrm{n}=10)\end{array}$ & $\begin{array}{c}\text { lower } \\
(n=20)\end{array}$ \\
\hline Age (year) & $32 \cdot 4 \pm 7 \cdot 2$ & $34 \cdot 1 \pm 6 \cdot 3$ & $29 \cdot 0 \pm 4 \cdot 5$ & $34 \cdot 0 \pm 9 \cdot 8$ \\
\hline Height $(\mathrm{cm})$ & $170 \cdot 6 \pm 9 \cdot 4$ & $169 \cdot 0 \pm 4 \cdot 8$ & $176 \cdot 4 \pm 6 \cdot 9 \# \#$ & $163 \cdot 7 \pm 8 \cdot 1$ \\
\hline Weight (kg) & $58 \cdot 9 \pm 8 \cdot 0$ & $55 \cdot 3 \pm 6 \cdot 9$ & $59 \cdot 9 \pm 7 \cdot 0$ & $55 \cdot 0 \pm 11 \cdot 7$ \\
\hline$\%$ Body Fat & $16 \cdot 6 \pm 5 \cdot 2$ & $19 \cdot 4 \pm 5 \cdot 8$ & $18 \cdot 4 \pm 5 \cdot 8$ & $19 \cdot 4 \pm 5 \cdot 9$ \\
\hline Lung Vital Capacity (1) & $4 \cdot 75 \pm 0 \cdot 76^{\star \star}$ & $4.00 \pm 0.59$ & $5 \cdot 04 \pm 0 \cdot 13 \# \#$ & $3.31 \pm 0.54$ \\
\hline LVC/predicted LVC (\%) & $115 \cdot 9 \pm 15 \cdot 3^{\star}$ & $99 \cdot 8 \pm 13 \cdot 2$ & $118 \cdot 6 \pm 22 \cdot 3 \# \#$ & $88 \cdot 0 \pm 13 \cdot 6$ \\
\hline LVC/Weight & $82 \cdot 0 \pm 15 \cdot 7$ & $75 \cdot 1 \pm 17 \cdot 7$ & $84 \cdot 1 \pm 17.1 \#$ & $62 \cdot 8 \pm 14 \cdot 3$ \\
\hline Upper Arm Girth (cm) & $33 \cdot 1 \pm 1 \cdot 4$ & $31 \cdot 7 \pm 3 \cdot 4$ & $31 \cdot 6 \pm 3 \cdot 0^{\star}$ & $28.7 \pm 3.9$ \\
\hline Grasping Force (kg) & $56 \cdot 7 \pm 9 \cdot 9$ & $53 \cdot 6 \pm 3 \cdot 4$ & $58 \cdot 0 \pm 9 \cdot 8 \#$ & $45 \cdot 7 \pm 8 \cdot 5$ \\
\hline Bullworker (kg) & $26 \cdot 9 \pm 3 \cdot 4$ & $26 \cdot 7 \pm 2 \cdot 5$ & & \\
\hline Wheelchair Weight (kg) & $8 \cdot 1 \pm 1 \cdot 8$ & $9 \cdot 6 \pm 2 \cdot 6$ & & \\
\hline
\end{tabular}

${ }^{\star} p<0.05,{ }^{\star \star} p<0.02, \# p<0.005, \# p<0.001$ indicating significant difference between the best placers and the lower ones. All other unmarked values were not significant at the 0.05 level.

work measurement (Brattgard et al., 1970). A rise in HR with arm exercise is also accompanied by a fall of cardiac stroke volume which is probably related to the inadequacy of the muscle pumps resulting in a decrease in venous return and an increase in anaerobic metabolism. However, Davies et al. (1974) reported that the volume of active muscle mass has been shown to be closely related with $\dot{\mathrm{VO}}_{2} \max$.

Zwiren and Bar-Or (1975) reported that the average $\dot{\mathrm{VO}}_{2}$ reached to 2070 $\mathrm{ml} / \mathrm{min}$ in athletic paraplegics. Corcoran et al. (1980) stated that the potentiality to achieve $\mathrm{VO}_{2}$ max for wheelchair athletes is higher than $2500 \mathrm{ml} / \mathrm{min}$ which is in accordance with the present data demonstrated during the race. But the present data is of submaximum value during the race indicating that the subjects were in excellent physical fitness. Pollack (1977) reported the $\dot{\mathrm{VO}}_{2}$ max of able-bodied elite runners range from 71.3 to $84.4 \mathrm{ml} / \mathrm{kg} / \mathrm{min}$ and they are able to run at a level of higher than 85 per cent of their $\max \mathrm{VO}_{2}$ during competition. His report may justify in part the present data compiled during the wheelchair full marathon.

In paraplegic athletes, both the muscles of the shoulder girdles and the arms are markedly hypertrophic. On the contrary, leg muscles are extremely atrophic. This is a major physiological difference between able-bodied and paraplegic athletes. Therefore, the work ratio of arms to legs between paraplegics and able-bodied athletes may approximate to near equal. By propelling a special wheelchair with small handrims during the race, paraplegics make fairly few thrusts per minute because of heavy resistance to their arms. With each thrust, the involved muscles may be able to exert near maximum power by this so called isokinetic exercise. Duration of contraction of the arm muscles to thrust the small handrim is longer but the muscles have a longer recovery time between each contraction. Therefore, Corcoran et al., (1980) stated that wheelchair athletes rely on aerobic power. Though wheelchair exercising has mechanically less efficiency and there may remain some unaerobic power involved in arm exercising that will limit $\mathrm{VO}_{2}$, relatively low $\mathrm{VO}_{2}$ of the present subjects suggests that paraplegic athletes may have a higher potential to take in more oxygen than is actually consumed.

It is surprising that the present elite subjects showed extremely high HR 
lasting more than 2 hours. This value can bear comparison with able-bodied elite athletes (Pollock, 1977; Barnard et al., 1979), which means that the cardiovascular function of paraplegic athletes has a potential to become equal to the able-bodied cardiovascular function if they have had vigorous training such as the present subjects had.

There appears to be no relationship between $\dot{\mathrm{V}}_{2}$ and speed during the race. There exists inter-individual variations in many factors such as the remaining active muscle mass, type of wheelchair, skill in manipulating a wheelchair on various road surfaces, psychological factors and the difference in ambiences between the laboratory and an actual race. The second place finisher of the half marathon demonstrated exceptionally high $\mathrm{HR}$ at regular intervals suggesting a highly developed racing strategy. Although these variations are inevitable, there must be some limits in the indirect method of measuring $\mathrm{VO}_{2}$ during the race, though further study is necessary.

The upper finishers had significantly greater pulmonary function than the lower finishers $(p<0.02)$. There were also significant differences in grasping force and arm girth. These are fundamental factors in improving the physical fitness of the paraplegic participants.

Paraplegics may have many other disadvantages such as orthostatic hypotension, autonomic hyperreflexia seen in higher spinal cord injury (Guttmann, 1976), a low basal metabolic rate (Clarke, 1966; Ogata et al., 1979), or body temperature disregulation. Corcoran (1980) reported that in a wheelchair marathon held on a cold rainy day, most of the entrants arrived at the goal line suffering from severe hypothermia and dehydration. Fortunately, because of the good weather conditions in the past three meetings, our subjects did not suffer from these problems. Though the environmental condition of a race is unpredictable, it is essential to provide useful aids such as fruit juice and towels as well as medical facilities along the race course.

\section{Conclusion}

1. The HR of paraplegic marathon runners during the race was extremely high continuously and was equal to that of able-bodied elite runners. However, $\mathrm{VO}_{2}$ was fairly low in comparison with able-bodied athletes.

2. Though the work ratio of arms to legs between paraplegics and able-bodied athletes may approximate to near equal, physiological and mechanical differences in arm work capacity of paraplegic athletes is likely to exist.

3. There was no significant difference in physical fitness between the paraplegic elite runners who took part in the full and in the half marathon.

4. Work output of paraplegic athletes may have a higher potential to uptake more oxygen than is actually consumed in the race.

5. Paraplegic wheelchair marathon is safe if environmental conditions are adequate for a race.

\section{Acknowledgements}

We would like to express our deep gratitude to the wheelchair atheletes for their cooperation. Our appreciation is also extended to Miss $\mathrm{N}$. Ishikawa (MT), Mr H. Takahashi (RPT), Mr J. Kobayashi (RPT) and Mr H. Ohkawa (RPT) for carrying out the experiments with the paraplegics. 


\section{Résumé}

Le marathon en fauteuil roulant est un des sports les plus eprouvants, et on a toujours ete sceptique quant a la securite de ce sport dans le cas des paraplegiques. La condition physique des paraplegiques a ete examinee reguliement depuis I'inauguration du Marathon International en Fauteuil roulant de Oita (semi-marathon) en 1981 . Le marathon complet $(42.195 \mathrm{~km})$ a ete adopte a la troisieme reunion (1983). Les equations individuelles entre le nombre de battements de coeur (NBC) et la consommation d'oxygene $\left(\mathrm{VO}_{2}\right)$ ont ete etablies d'apres les tests preliminaires sur les sujets envisages comme les meilleurs finisseurs de ces courses. En comparaison des coureurs d'elite sans handicap, $\dot{\mathrm{VO}}_{2}$ estime indirectement au cours du marathon complet a indique une valeur assez basse $(35.0 \pm 3.8 \mathrm{ml} / \mathrm{kg} / \mathrm{min})$, tandis que NBC etait continuellement tres eleve (171.6 \pm 20.5 batte./min). Bien que le rapport entre la masse des muscles actifs des bras et celle des jambes chez les athletes paraplegiques se rapproche de 1 , les bras des paraplegiques semblent fournir une energie moins effective du point de vue physiologique et mecanique. Il n'a pas ete observe de differences significatives de condition physique entre les finisseurs d'elite de course complete et de semi-course. Dans l'ensemble de la condition physique, la fonction cardiovasculaire des athletes paraplegiques ne cede en rien a celle des athletes sans handicap. Le marathon complet en fauteuil roulant est un sport sur s'il est mene dans un environnement approprie.

\section{Zusammenfassung}

Der Rollstuhl-Marathonlauf ist eine der schwertsen Sportarten, doch es bestehen Zweifel uber die Sicherheit der Paraplegiker. Die korperliche Tauglichkeit von Paraplegikern wurde seit dem Eroffnen des Internationalen Marathons in Oita (Halbmarathon) im Jahre 1981 untersucht. 1983 wurde bei der 3. Veranstaltung ein Vollmarathon $(42 \cdot 195 \mathrm{~km})$ eingef uhrt. Die einzelnen Gleichungen zwischen Herzf requenz (HR) und Sauerstoffverbrauch $\left(\dot{\mathrm{V}} \mathrm{O}_{2}\right)$ wurden aufgrung von vorlaufigen Proben bei Athleten erstellt, von denen gute Platzierungen erwartet wurden. Beim Vollrennen wurde der $\dot{\mathrm{VO}}_{2}$ indirekt berechnet und wies einen ziemlich niedrigen Wert von $35.0 \pm 3.8 \mathrm{ml} / \mathrm{kg} / \mathrm{min}$ im Vergleich mit ganz gesunden Eliterennern auf, jedoch die Herzfrequenz war andauernd ausserst hoch $(171 \cdot 6 \pm 20 \cdot 5 \mathrm{Herzschlage} / \mathrm{min})$. Obwohl das Verhaltnis von aktiver Muskelmenge zwischen Armen und Beinen bei paraplegischen Athleten fast gleich ist, haben die Arme der Paraplegiker physiologisch und mechanisch eine weniger wirksame Kraft. Es ergab sich kein wesentlicher Unterschied in korpelicher Tauglichkeit zwischen Vollelite und Halbelite Wettwerbern. Die Kardiovaskularfunktion der paraplegischen Athleten kann mit der von ganz gesunden Athleten als ebenburtig betrachtet werden. Marathonlaufen ist nicht gefahrlich, wenn es in einer geeigneten Umgebung veranstaltet wird.

\section{References}

ANDERSEN KL, SMITH-SiverTSEN J 1966 Evaluation of work power and exercise tolerance. In: Yoshimura, H, Weiner JS (eds) Human Adaptability and Its Methodology, pp. 183-203, Japan Society for the Promotion of Sciences, Tokyo

Asayama K, Nakamura Y, Ogata H et al. 1984 Energy expenditure of paraplegic marathon runners measured during a wheelchair marathon. J UOEH 6:121-130

ASMUSSEN E, HEMMINGSEN I 1958 Determination of maximal working capacity at different ages in work with the legs or with the arms. Scandinavian Journal of Clinical and Laboratory Investigation 10: 67-71

Åstrand P, RoDAHL K 1977 Evaluation of physical work capacity on the basis of tests. In: Textbook of Work Physiology. McGraw-Hill, pp. 331-365, New York. 365

Åstrand P, SALTIN B 1961 Maximal oxygen uptake and heart rate in various types of muscular activity. Journal of Applied Physiology 16: 977-981

Baldwin ED, Cournand A, Richards DW 1950 Pulmonary insufficiency. 1. Physiological classification, clinical methods of analysis, standard values in normal subjects. Medicine 27:243-278

BARNARD RJ, GRIMditch GK, WilmoRE JH 1979 Physiological characteristics of sprint and endurance Masters runners. Medicine and Science in Sport 11:167-171

BAR-OR O, ZWIREN LD 1975 Maximal oxygen consumption test during arm exercise-reliability and validity. Journal of Applied Physiology 38:424-426

BRATtgard SO, Grimby G, Hook H 1970 Energy expenditure and heart rate in driving a wheelchair ergometer. Scandinavian Journal of Rehabilitation Medicine 2:143-148

Clarke KS 1966 Caloric costs of activity in paraplegic persons. Archives of Physical Medicine and Rehabilitation 47:427-435 
Corcoran PJ, Goldman RF, Hoerner EF et al. 1980 Sports medicine and the physiology of wheelchair marathon racing. Orthopedic Clinics of North America 11:697-716

Davies CTM, SARgeant AJ 1974 Physiological responses to standardised arm work. Ergonomics 17:41-49

GutTMANN L 1976 Disturbances of vasomotor control. In: Spinal Cord Injuries, 2nd edn, pp. 295-304, Blackwell Scientific Publication, Oxford

HJELTNES N, VOKAC Z 1979 Circulatory strain in everyday life of paraplegics. Scandinavian Journal of Rehabilitation Medicine 11:67-73

Ogata H, Asayama K, Morita H. et al. 1979 The adaptation to seasonal environmental variations seen in patients with spinal cord injury. J UOEH 1:351-359

Pollock ML 1977 Submaximal and maximal working capacity of elite distance runners. Annals of the New York Academy of Sciences 301:310-322

Rowell LB, TAYLOR HL, WANG Y 1964 Limitations to prediction of maximal oxygen intake. Journal of Applied Physiology 19:919-927

Stenberg J, Åstrand P, EkBlom B et al. 1967 Hemodynamic response to work with different muscle groups, sitting and supine. Journal of Applied Physiology 22:61-70

VoKAC Z, Bell H, BAUTZ-Holter E. et al. 1975 Oxygen uptake/heart rate relationship in leg and arm exercise, sitting and standing. Journal of Applied Physiology 39:54-59

WILSON PK, FARDY PS, FROELICHER VF 1981 Physical measurements. In: Cardiac Rehabilitation, Adult fitness and Exercise Testing, pp. 237-241, Lea \& Febiger, Philadelphia.

WYNDHAM CH, WARD JS 1957 An assessment of the exercise capacity of cardiac patient. Circulation 16:384-393

ZWIREN LD, BAR-OR O 1975 Responses to exercise of paraplegics who differ in conditioning levels. Medicine and Science in Sports 7:94-98 